\title{
Estimation of the local production of antibodies to Treponema pallidum in the central nervous system of patients with neurosyphilis
}

\author{
F MÜLLER AND M MOSKOPHIDIS \\ From the Division of Serology, Department of Medical Microbiology, Institute of Hygiene, Hamburg, \\ West Germany
}

SUMMARY In $76 \%$ of 149 patients with neurosyphilis local production of treponema-specific IgG antibodies in the central nervous system (CNS) was determined by estimating the cerebrospinal fluid (CSF)-to-serum ratio of TPHA-IgG titre per mg total IgG. With this formula synthesis of treponema-specific IgG antibodies in the CNS could be detected independently of the function of the blood-CSF barrier. A selective increase of total IgG in the CSF was not found in all cases. Forty-three patients with adequately treated or spontaneously resolved syphilis without clinical evidence of involvement of the CNS by Treponema pallidum served as controls.

\section{Introduction}

The concentration of albumin, IgG, and other proteins in the cerebrospinal fluid (CSF) of healthy adults depends on their concentrations in the serum. ${ }^{1}$ The serum-to-CSF ratio of albumin is usually about 220. This has proved to be a reliable indicator of the function of the blood-CSF barrier, since albumin is not synthesised in the central nervous system (CNS) but is derived entirely from serum. The serum-toCSF ratio of IgG is about $450 .^{1-4}$

In patients with inflammation of the CNS the transudation of serum proteins into the CSF is increased as a result of the increased permeability of the blood-CSF barrier; this reduces the serum-toCSF ratio of all proteins. On the other hand T and $B$ lymphocytes may infiltrate the CNS during acute infections and result in local synthesis of immunoglobulins. ${ }^{5}$

An increase in total IgG in the CSF of patients with neurosyphilis is thought to be the result of local production of antibodies to Treponema pallidum. ${ }^{67}$ More specific evidence of the local synthesis of specific immunoglobulins can be gained by serological tests which show a reduced serum-to-CSF ratio of antibodies to $T$ pallidum.

Address for reprints: Professor F Müller, Institute of Hygiene, Gorch-Foch-Wall 15/17, D-2000 Hamburg 36, FRG

Accepted for publication 22 September 1982
The present study was undertaken to determine whether the production of treponema-specific antibodies in the CNS of patients with neurosyphilis is independent of the function of the blood-CSF barrier and the selective increase in total IgG in the CSF. For this purpose we measured the serum-toCSF ratios of albumin, total IgG, and treponemaspecific IgG as well as the CSF-to-serum ratio of treponemal IgG per mg of total IgG in patients with syphilis both with or without clinical features of neurosyphilis.

\section{Materials and methods}

SERUM AND CEREBROSPINAL FLUID SAMPLES Paired samples of serum and CSF were collected on the same day from 212 patients with several different clinical disorders attending neurological clinics. A diagnosis of syphilis was made when the $T$ pallidum haemagglutination assay (TPHA) and the fluorescent treponemal antibody-absorption (FTA-ABS) test on the patients' sera gave positive results. In each case a detailed history, including that of specific treatment, was obtained.

QUANTITATIVE DETERMINATION OF ALBUMIN AND TOTAL IgG

Quantification of albumin and total IgG in serum and CSF samples was carried out by single radial immunodiffusion using Partigen plates (Behringwerke, Marburg, Germany). 
DETERMINATION OF TREPONEMA-SPECIFIC IgG TITRE/MG TOTAL IgG

In detecting antibodies against pathogenic treponemes the specificity of the TPHA was higher than 99.9\%.$^{8}$ The specificity of the test on CSF samples was as high as that on sera. The test was carried out quantitatively according to the manufacturer's instructions (Fujizoki Pharmaceuticals, Tokyo, Japan). Total TPHA titres were estimated by the dilution of $25 \mu$ l serum or CSF in absorbing diluent at a starting dilution of $1 / 5$ (serum) or $1 / 1$ (CSF). If treponemal IgM antibodies were found in the sample the TPHA-IgG titre was calculated by subtracting the TPHA-IgM titre (see below) from the total TPHA titre.

The specific TPHA-IgG titre per mg total IgG was calculated from the TPHA-IgG titre in the serum or CSF divided by the total IgG in $\mathrm{mg} / 25 \mu \mathrm{l}$.

\section{FRACTIONATION OF SERA AND CSF BY GEL FILTRATION}

Separation of IgM from IgG antibodies in the sera or CSF was carried out by Ultrogel AcA 34 filtration according to the method of Müller and Oelerich. ${ }^{9}$ Briefly, $0.7 \mathrm{ml}$ of the sample was filtered through a $1.5 \times 14 \mathrm{~cm}$ gel column using phosphate-buffered saline, $\mathrm{pH} 7 \cdot 3$. Fractions of $1 \cdot 3 \mathrm{ml}$ were collected and the absorbance at $280 \mathrm{~nm}$ measured.

\section{S(IgM)-TPHA TEST}

The method used for this test was that described by Müller and Lindenschmidt. ${ }^{10}$ Fractions from the first peak absorbance (IgM) after gel filtration of serum or CSF were titrated (starting dilution 1/1) using the sensitised erythrocytes of the TPHA test as antigen. The titres obtained were multiplied by 6 (the dilution factor of the gel filtrate). The specificity of the 19S(IgM) treponema-specific antibodies was shown by the 19S(IgM)-FTA-ABS technique.

\section{S(IgM)-FTA-ABS TEST}

The technique for demonstrating treponema-specific 19S(IgM) antibodies in the fractions after gel filtration has been described. ${ }^{9-11}$ The Nichols strain of pathogenic $T$ pallidum was used as antigen. For the detection of $19 \mathrm{~S}(\mathrm{IgM})$ treponema-specific antibodies
FITC-labelled anti-human IgM serum from rabbits with $\mu$-chain specificity (Dako Immunochemicals, Copenhagen, Denmark) was used at a working dilution of $1 / 50$.

\section{Results}

The patients were divided into nine groups on the basis of the serum-to-CSF ratios of albumin, total IgG, TPHA-IgG titre, and the CSF-to-serum ratio of TPHA-IgG titre per mg total IgG.

Group la-In 43 patients syphilis had been treated satisfactorily or had resolved spontaneously. From the mean concentrations, standard deviations (2 SD), and ranges for albumin and total IgG concentrations in the sera and CSF it can be seen that neither the function of the blood-CSF barrier nor the CNS was affected by the treponemal infection (table I). Treponema-specific IgM antibodies could not be detected in the serum or in the CSF of these patients. Correspondingly, the serum-to-CSF ratios of albumin and total IgG were within the normal range (table II). The concentrations of TPHA-IgG antibodies in $1 \mathrm{mg}$ total $\mathrm{IgG}$ were equal in both serum and CSF. The mean value of the CSF-toserum ratio was 1 .

Group $1 b$-Normal values were found in 13 patients with untreated secondary syphilis who had no clinical or biochemical evidence of $\mathrm{CNS}$ involvement (table II). Sera from all of these patients were reactive in the $19 \mathrm{~S}(\mathrm{IgM})-\mathrm{FTA}-\mathrm{ABS}$ test.

Group Ic-Normal values were found in 10 patients with adequately treated neurosyphilis but residual symptoms of tabes dorsalis or general paralysis of the insane.

Groups $2 a$ and $2 b$-Of 81 patients with neurosyphilis with normal serum-to-CSF albumin ratios, 48 had normal serum-to-CSF ratios of total IgG but reduced ratios of TPHA-IgG and increased CSF-to-serum ratios of TPHA-IgG titre per mg total IgG. In 33 of the 81 patients with neurosyphilis an increase of total IgG as well as of TPHA-IgG in the CSF was shown by reduced serum-to-CSF ratios. The CSF-to-serum ratio of TPHA-IgG titre per mg total IgG was raised appreciably in each patient. The TPHA-IgG titres per mg of total IgG in the serum

TABLE I Mean values, standard deviation (2 SD), and range of concentrations of albumin and IgG in the sera and CSF of patients whose infection with syphilis had been treated or had resolved spontaneously without involvement of the CNS

\begin{tabular}{llllllll}
\hline & \multicolumn{2}{l}{ Albumin $(\mathrm{mg} / \mathrm{l})$} & & & \multicolumn{2}{c}{ Total IgG $(\mathrm{mg} / \mathrm{l})$} \\
\cline { 2 - 4 } & Mean & 2 SD & Range & & Mean & 2 SD & Range \\
\hline Serum & 39900 & 15500 & $24600-54900$ & 11500 & 5200 & $7100-18600$ \\
CSF & 198 & 120 & $102-304$ & 29 & 20 & $13-47$ \\
\hline
\end{tabular}


TABLE II Findings in 149 patients with neurosyphilis, 20 patients without neurosyphilis, and 43 controls

\begin{tabular}{|c|c|c|c|c|c|c|c|c|c|}
\hline \multirow[b]{3}{*}{ Group ${ }^{*}$} & \multirow{3}{*}{$\begin{array}{l}\text { No of } \\
\text { patients }\end{array}$} & \multicolumn{6}{|c|}{ Serum-to-CSF ratio of: } & \multirow{2}{*}{\multicolumn{2}{|c|}{$\frac{C S F \text {-to-serum ratio of: }}{T P H A \text {-IgG titre/mg IgG }}$}} \\
\hline & & \multicolumn{2}{|c|}{ Albumin } & \multicolumn{2}{|l|}{$\lg G$} & \multicolumn{2}{|c|}{ TPHA-IgG titre } & & \\
\hline & & Mean & Range & Mean & Range & Mean & Range & Mean & Range \\
\hline la & 43 & 220 & $143-392$ & 446 & $268-851$ & 445 & $320-640$ & $1 \cdot 0$ & $0 \cdot 5-2 \cdot 0$ \\
\hline $1 \mathrm{~b}$ & 13 & 226 & $149-366$ & 460 & $316-485$ & 440 & $320-640$ & 0.9 & $0 \cdot 5-1 \cdot 9$ \\
\hline 1c & 10 & 208 & $159-268$ & 378 & 273-568 & 378 & $320-512$ & $1 \cdot 0$ & $0 \cdot 6-1 \cdot 8$ \\
\hline $2 \mathbf{a}$ & 48 & 230 & $143-397$ & 441 & $268-742$ & 48 & $0 \cdot 6-160$ & 41 & $3 \cdot 0-430$ \\
\hline $2 \mathrm{~b}$ & 33 & 203 & $146-390$ & 158 & $36-257$ & 18 & $0 \cdot 2-80$ & 31 & $3 \cdot 0-178$ \\
\hline $3 \mathbf{a}$ & 14 & 84 & $9-122$ & 130 & $17-255$ & 89 & $10-160$ & $1 \cdot 4$ & $0 \cdot 8-2 \cdot 0$ \\
\hline $3 \mathrm{~b}$ & 34 & 109 & $31-139$ & 145 & $10-263$ & 20 & $1-80$ & 19 & $3 \cdot 0-139$ \\
\hline $4 a$ & 10 & 110 & $80-126$ & 226 & $174-261$ & 320 & $317-320$ & 0.7 & $0 \cdot 6-1 \cdot 0$ \\
\hline $4 b$ & 7 & 96 & $26-135$ & 165 & $32-267$ & 494 & $320-640$ & $0 \cdot 3$ & $0 \cdot 1-0 \cdot 4$ \\
\hline
\end{tabular}

*Group 1a-adequately treated or spontaneously resolved syphilis without symptoms of neurosyphilis; group 1b-untreated secondary syphilis without symptoms of neurosyphilis; group 1c-adequately treated neurosyphilis with characteristic symptoms; group 2a-neurosyphilis with intact blood-CSF barrier and normal total IgG in the CSF; group $2 b$-neurosyphilis with intact blood-CSF barrier, selective i increase of total IgG in the CSF, and local synthesis of treponema-specific IgG antibodies; group 3a-neurosyphilis with dysfunction of the $\mathbb{C}$ blood-CSF barrier without local synthesis of treponema-specific IgG antibodies; group $3 b$-neurosyphilis with dysfunction of the blood-CSF $\mathrm{N}$ barrier with local synthesis of treponema-specific IgG antibodies; group 4a-neurosyphilis without local synthesis of treponema-specific IgG 0 antibodies; group $4 \mathrm{~b}$-syphilis with synthesis of treponema-non-specific IgG in the CNS.

and CSF of patients with neurosyphilis (groups $2 \mathrm{a}$ and $2 \mathrm{~b}$ ) are shown in fig 1 . In both groups the corresponding values were up to $2 \cdot 6 \log _{10}$ higher in the CSF than in the serum.

Groups $3 a$ and $3 b$-Patients in these two groups with neurosyphilis had a reduced serum-to-CSF albumin ratio. In the 14 patients in group $3 a$ the TPHA-IgG titres per $\mathrm{mg}$ total IgG were identical in both serum and CSF. This ratio was, however, increased in the 34 patients in group $3 \mathrm{~b}$ (table II).

Groups $4 a$ and $4 b$-The blood-CSF barrier of patients with syphilis was also disturbed (table II). In each patient in group $4 a$ the ratio of treponemaspecific IgG antibody was normal but the total IgG in the CSF was increased. A non-specific increase of total IgG in the CSF was found in the patients in group $4 \mathrm{~b}$. The CSF-to-serum ratio of TPHA-IgG titre per $\mathrm{mg}$ total $\mathrm{IgG}$ was below the lowest normal value of 0.5 .

The TPHA-IgG titres per mg total IgG in the serum of the patients with dysfunction of the bloodCSF barrier are plotted against those in the CSF in fig 2 . The patients of group $3 \mathrm{~b}$ with higher values in the CSF than in the serum are located above the dotted lines (normal range). The patients in groups $3 a$ and $4 a$ (values within the dotted lines) had similar CSF and serum TPHA-IgG titres per mg total IgG. Below the normal range (group $4 \mathrm{~b}$ ) the TPHA-IgG titres per $\mathrm{mg}$ total $\mathrm{IgG}$ were lower in the CSF than in the serum.

\section{Discussion}

At present involvement of the CNS in syphilis is diagnosed by reactive TPHA or FTA-ABS test results on the CSF of patients with clinical features of

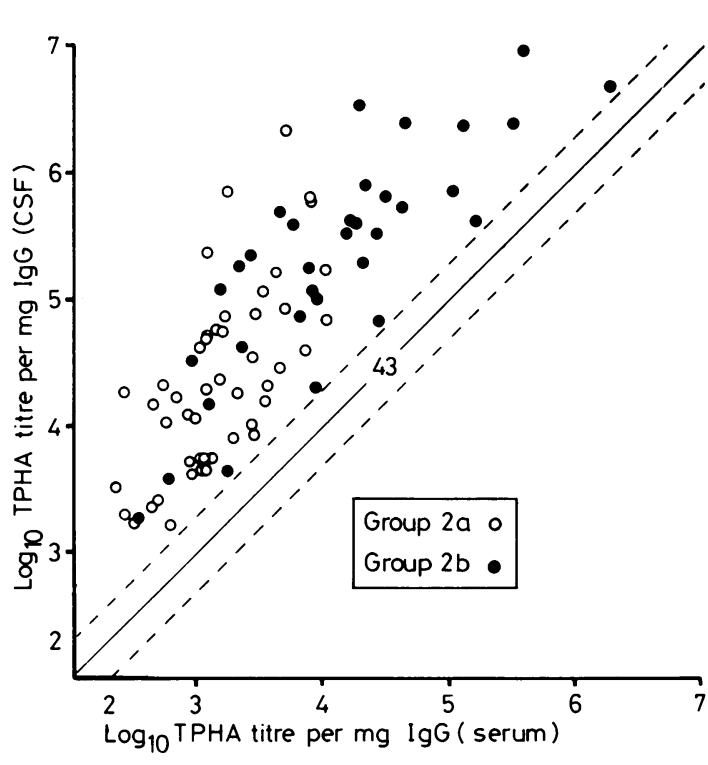

FIG 1 Correlation of the TPHA-IgG titre per $\mathrm{mg}$ total $\mathrm{IgG}$ in CSF and serum of patients without dysfunction of the blood-CSF barrier. The dotted lines indicate the normal range of correlation (group la).

the disease, white cell count in the CSF, and the estimation of the serum-to-CSF ratios of albumin $\stackrel{9}{+}$ and total IgG. Since the introduction of the FTAABS test and the TPHA treponema-specific IgG antibodies can be estimated quantitatively in serum and CSF.

The specificity of TPHA-IgG titres in the CSF is as high as in the serum. This can be shown by the 


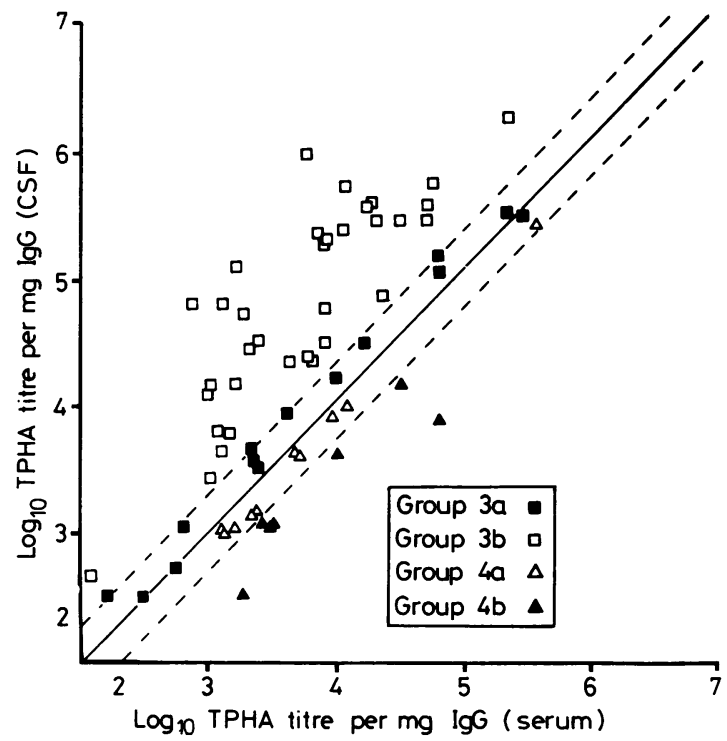

FIG 2 Correlation of the TPHA-IgG titre per mg total $\mathrm{IgG}$ in CSF and serum of patients with dysfunction of the blood-CSF barrier. The dotted lines indicate the normal range of correlation (group la).

finding of a normal serum-to-CSF ratio of TPHAIgG titre in the groups of patients with syphilis but without involvement of the CNS. Parallel investigations in several patients using the IgG-FTA-ABS test instead of the TPHA-IgG test gave identical results. For this study we chose the TPHA because of its higher sensitivity to treponemal antibodies.

The following formula:

TPHA-IgG titre per mg total IgG (CSF)

TPHA-IgG titre per mg total IgG (serum)

was used firstly in patients with syphilis without clinical and biochemical signs of CNS involvement, that is with a normal white cell count and without local synthesis of total IgG in the CSF or dysfunction of the blood-CSF barrier (group 1a). The serum-toCSF ratio of treponema-specific IgG per mg total IgG was 1 (range $0 \cdot 5-2 \cdot 0$ ). This means that in these patients the concentrations of TPHA-IgG antibodies per.mg total IgG were equal in serum and CSF. Furthermore, the serum-to-CSF ratio of TPHA-IgG titre correlated with the total IgG as well as with the values of normally occurring IgG antibodies. ${ }^{12}$ These observations indicate that local synthesis of treponema-specific IgG does not take place in the CNS and that the treponemal IgG antibodies in the CSF are derived solely from the serum by transfer through the intact blood-CSF barrier.
Using the above formula local production of treponema-specific IgG can be shown in patients with a normal cell count and normal concentration of total IgG in the CSF, indicating involvement of the CNS in the treponemal infection (group 2a). In the patients in group $2 \mathrm{~b}$ an increase in total $\mathrm{IgG}$ in the CSF was related to the synthesis of treponemaspecific IgG in the CNS.

In the 14 patients in group $3 a$ the reduced serumto-CSF ratio of TPHA-IgG titre was caused by an increased inflow of treponema-specific IgG antibodies from the serum into the CSF as a result of dysfunction of the blood-CSF barrier. This was shown by identical TPHA-IgG titres per mg total IgG in both serum and CSF. Local synthesis of treponemal IgG antibodies can also occur in patients with a breakdown of the blood-CSF barrier as shown by the increased CSF-to-serum ratio of TPHA-IgG titres per $\mathrm{mg}$ total $\mathrm{IgG}$ in the $\mathbf{3 4}$ patients in group $\mathbf{3 b}$.

From the results of the patients with neurosyphilis local production of treponema-specific IgG in the CNS occurred in more than $76 \%$ of cases. The formula shows that non-specific local production of IgG occurs in the CNS of patients with syphilis with neurological symptoms independent of the treponemal infection (group 4b). This might be explained by an inflammation of the CNS which is independent of the treponemal infection.

The boundaries between groups $2 a$ and $2 b$ as well as between groups $3 a$ and $3 b$ were fluid (figs 1 and 2 ). This is not surprising since in each patient time elapses between infection and healing and the numbers of treponema-specific IgG-producing B lymphocytes diminish at different rates from the CNS.

In the patients in this study no correlation could be seen between local production of treponema-specific IgG antibodies in the CNS and clinically characteristic symptoms of neurosyphilis (tabes dorsalis, paralysis, meningovascular neurosyphilis). About one-fourth of the patients in whom synthesis of treponemal IgG antibodies in the CNS occurred had no apparent neurological symptoms (clinically asymptomatic syphilis) (unpublished data).

Our findings confirm those of Schliep and Felgenhauer, ${ }^{7}$ who noted raised titres of treponemaspecific antibodies in the CSF of patients with neurosyphilis and assumed that local synthesis of these antibodies had taken place in the CNS.

It is noteworthy that there was a parallel between the local production of treponema-specific antibodies in the CNS and the appearance of oligoclonal IgG bands in the CSF. In about $75 \%$ of the patients with neurosyphilis oligoclonal IgG bands could be seen in the CSF (unpublished data). This agrees with the findings of Vartdal et $a l^{13}$ and Strandberg 
Pedersen $e t a l,{ }^{14}$ who found intrathecal synthesis of oligoclonal IgG antibodies with treponemal specificity in patients with untreated neurosyphilis.

The above formula can be modified and used to demonstrate local synthesis of treponema-specific IgM antibodies in the CNS in patients with inflammation of the CNS in latent or late latent treponemal infections.

\section{References}

1. Felgenhauer K. Protein size and cerebrospinal fluid composition. Klin Wochenschr 1974;52:1158-64.

2. Tourtellotte W. On cerebrospinal fluid immunoglobulin-G (IgG) quotients in multiple sclerosis and other diseases. $J$ Neurol Sci 1970; 10:279-304.

3. Ganrot K, Laurell C-B. Measurement of IgG and albumin content of cerebrospinal fluid, and its interpretation. Clin Chem 1974; 20:571-3.

4. Weisner B, Bernhardt W. Zusammenhang der ImmunglobulinKonzentration in Liquor und Serum. Fortschr Med 1978;96: 1865-9.

5. Sandberg-Wollheim $M_{r}$ Zettervall $O$, Müller $R$. In-vitro synthesis of IgG by cells from the cerebrospinal fluid in a patient with multiple sclerosis. Clin Exp Immunol 1969;4: 401-5.
6. Schliep G, Felgenhauer K. Serum-CSF protein gradients, the blood-CSF barrier and the local immune response. $J$ Neurol 1978; 218:77-96.

7. Schliep G, Felgenhauer K. Die lokale humorale Immunantwort bei der Neurosyphilis. In: Reisner H, Schnabert G, eds. Fortschr der Techn Medizin in der Neurol Diagnostik und Therapie. Vienna: Neurologische Universităts-Klinik 1980;613.

8. Müller F. Der Treponema-Pallidum-Hämagglutinations(TPHA)-Test. Prinzip, Aussagekraft und bisherige Erfah rungen. Akt Dermatol 1976; 2:123-30.

9. Muller F Oelerich S. A modified technique of the IgM-FTA ABS test for the demonstration of competitively inhibited antibodies in syphilis. Das Arztliche Laboratorium 1978;24: 386-91.

10. Müller F, Lindenschmidt E-G. Demonstration of specific 19S(IgM) antibodies in untreated and treated syphilis. Comparative studies of the 19S(IgM)-FTA test, the 19S(IgM-TPHA test, and the solid-phase haemadsorption assay. $\mathrm{Br} J$ Vener Dis 1982; 58: $12-7$.

11. Müller F. The 19S(IgM)-FTA-ABS test in the serodiagnosis of syphilis. Technique, sources of error and diagnostical information of results. Immun Infekt 1982; 10:23-34.

12. Fossan GO. The transfer of IgG from serum to CSF, evaluated by means of a naturally occurring antibody. Eur Neurol 1977; 15:231-6.

13. Vartdal F, Vandvik B, Michaelsen TE, Loe K, Norrby E. Neurosyphilis: intrathecal synthesis of oligoclonal antibodies to Treponema pallidum. Ann Neurol 1982;11:35-40.

14. Pedersen NS, Kam-Hansen S, Link H, Mavra, M. Specificity of immunoglobulins synthesized within the central nervous system in neurosyphilis. Acta Pathol Microbiol Scand (C) 1982;90:97-104. 